\title{
Identification of Isomeric N-Glycan Structures by Mass Spectrometry with 157 nm Laser- Induced Photofragmentation
}

\author{
Arugadoss Devakumar, Yehia Mechref, Pilsoo Kang, Milos V. Novotny, \\ and James P. Reilly \\ Department of Chemistry, Indiana University, Bloomington, Indiana, USA
}

Characterization of structural isomers has become increasingly important and extremely challenging in glycobiology. This communication demonstrates the capability of ion-trap mass spectrometry in conjunction with $157 \mathrm{~nm}$ photofragmentation to identify different structural isomers of permethylated N-glycans derived from ovalbumin without chromatographic separation. The results are compared with collision-induced dissociation (CID) experiments. Photodissociation generates extensive cross-ring fragment ions as well as diagnostic glycosidic product ions that are not usually observed in CID MS/MS experiments. The detection of these product ions aids in characterizing indigenous glycan isomers. The ion trap facilitates $\mathrm{MS}^{n}$ experiments on the diagnostic glycosidic fragments and cross-ring product ions generated through photofragmentation, thus allowing unambiguous assignment of all of the isomeric structures associated with the model glycoprotein used in this study. Photofragmentation is demonstrated to be a powerful technique for the structural characterization of glycans. (J Am Soc Mass Spectrom 2008, 19, 1027-1040) @ 2008 American Society for Mass Spectrometry

G lycans are biomolecules consisting of one or more monosaccharide units that are covalently $\mathrm{N}$ - or O-linked to a protein as one of the most common post-translational modifications. They are either linear, consisting of repeating monosaccharide rings (commonly observed for O-linked glycans), or branched with multiple glycosidic linkages between monosaccharide units $[1,2]$. Their crucial role in a wide range of biological processes, including inter- and intracellular activities [3], coordination of immune functions [4], therapeutics [5], and protein regulations and interactions [6], is widely acknowledged [7]. To improve our understanding of these processes, it is important to explore glycan structure-function relationships. However, the detailed characterization of a glycan structure and its attributes remains a difficult task, given the microheterogeneity and diversity of these molecules. Importantly, the discrimination of numerous structural isomers differing in sequence, linkage, position, or branching features remains a challenging frontier of glycobiology.

For years, the characterization of glycan structures has almost exclusively been accomplished by tandem mass spectrometry (MS/MS) $[1,8,9]$ because of its high sensitivity and minimum sample requirements relative to nuclear magnetic resonance (NMR). Different combinations of ionization techniques, ion activation, and

Address reprint requests to Prof. James P. Reilly, Indiana University, Department of Chemistry, Chemistry Building, 800 E. Kirkwood Ave., Bloomington, IN 47405-4001. E-mail: reilly@indiana.edu mass analyzers have been used, including fast atom bombardment (FAB)-MS [10-12], infrared-laser desorption MS [13, 14], matrix-assisted laser desorption/ionization (MALDI)/magnetic sector MS [15-17], electrospray ionization (ESI)-MS [18, 19], MALDI/time-offlight (TOF)-MS [20-22], ESI ion-trap MS [23-25], MALDI Fourier transform MS [26], ESI- or MALDIbased quadrupole/TOF-MS [27-30], MALDI/Postsource Decay (PSD) TOF-MS [31-33], and, more recently, MALDI-TOF/TOF-MS [34-38].

A glycan ion generally fragments in two ways: (1) glycosidic cleavages resulting from a bond rupture between two adjacent sugar residues and (2) cross-ring cleavages in which any two bonds on the same sugar unit are broken. Cross-ring fragment ions are commonly observed in high-energy collision-induced dissociation (CID) methods as demonstrated in the tandem TOF/TOF approach [34-38]. A limitation of this technique, however, is its inability to perform multistage tandem mass spectrometry experiments. On the other hand, glycosidic cleavage ions are predominantly observed in low-energy activation methods and are mainly used to derive sequence and limited branching information. Most recently, Reinhold and co-workers [39] demonstrated the use of low-energy activation to identify the structural isomers of glycans in complex mixtures with the help of sequential tandem mass spectrometry $\left(\mathrm{MS}^{n}\right)$. However, a disadvantage of CID is the decrease in both the degree and efficiency of dissociation with increasing mass and $\mathrm{MS}^{n}$ events. Alternatively, other activation techniques have been used for 
$\mathbf{X} 20$

(a)

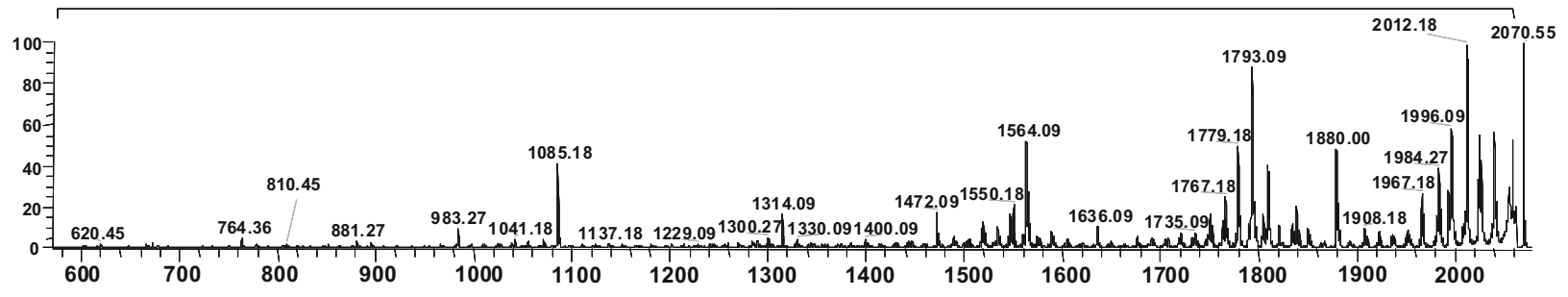

$\times 6$

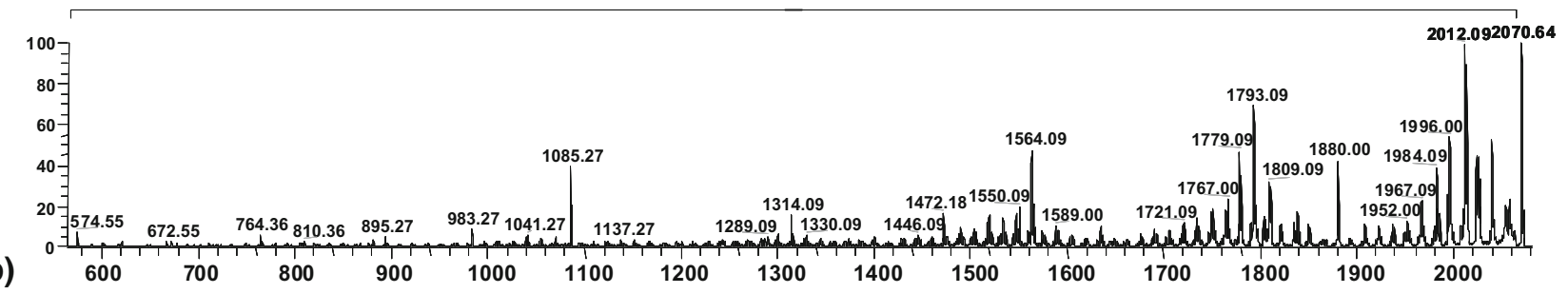

$\times 3$

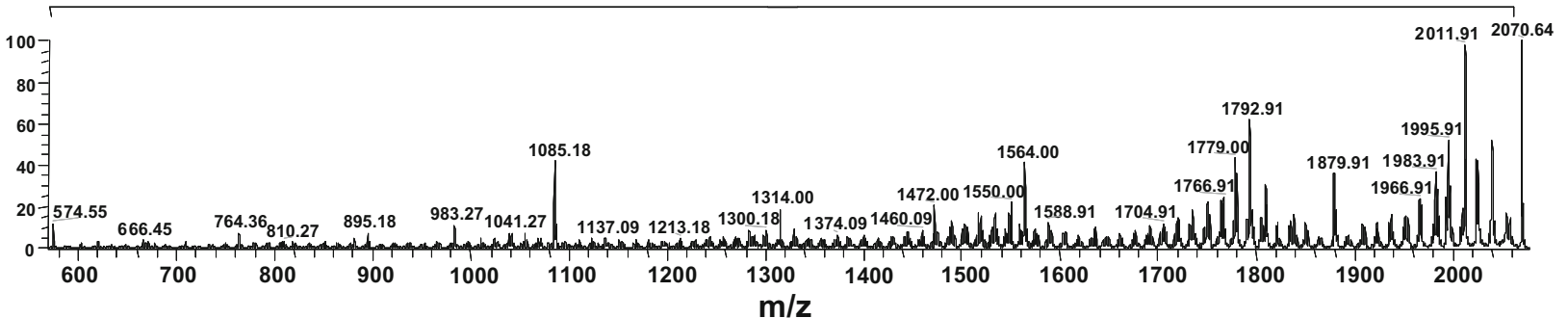

Figure 1. Comparison of photodissociation spectra obtained by (a) 1, (b) 2, and (c) 3 laser shots from $[\mathrm{M}+\mathrm{Na}]^{+}$permethylated glycan ion $\mathrm{m} / z 2071$ of hen ovalbumin.

the structural characterization of glycans, including infrared multiphoton dissociation (IRMPD) [40-43] and electron capture dissociation (ECD) [44, 45]. Although IRMPD and CID are both low-energy vibrational excitation techniques, Lebrilla and coworkers [42] have shown that the fragmentation efficiency of IRMPD increases with increasing oligosaccharide size. Recent efforts in the fragmentation of various metal-cationized oligosaccharides by ECD have provided structural information complementary to IRMPD [45].

Recently, we reported that $157 \mathrm{~nm}$ laser photodissociation of peptide ions generates high-energy backbone and side-chain cleavages [46-48]. On the basis of previous spectroscopic studies, we proposed that the chromophore involved in this process is the backbone amide. The preferential cleavage between the $\alpha$ - and carbonyl-carbon atoms of singly charged peptides having C- or N-terminal arginine yielded uniform and easily interpretable distributions of $x$ - and $a$-type ions. We recently expanded the utility of photofragmentation to the characterization of native and derivatized linear oligosaccharides as well as permethylated acidic glycans [49, 50]. Photodissociation yielded intense cross-ring fragmentation of Girard's T derivatized oligosaccharides and the product ions correspond to high-energy fragmentation pathways [49]. Sig- nificant progress has been reported with different permethylated glycan structures, including sialylated linear and branched, high-mannose type and fucosylated, complex types [50]. In the present study, we report further results with photofragmentation of selected permethylated $\mathrm{N}$-glycans derived from ovalbumin. In particular, we explore the potential of using an ion-trap mass spectrometer to perform $\mathrm{MS}^{n} \mathrm{CID}$ experiments on the characteristic photofragment ions.

\section{Experimental}

\section{Materials}

Ovalbumin (chicken egg white), endoglycosidase peptide- $N$-glycosidase (PNGase F; EC 3.4.1.52), dihydroxy benzoic acid (DHB), sodium acetate, mercaptoethanol, and dimethyl sulfoxide (DMSO) were purchased from Sigma Chemical Company (St. Louis, MO, USA). Sodium hydroxide 20-40 mesh beads were obtained from Aldrich (Milwaukee, WI, USA). Micro spin-columns, suitable for volumes from 25 to $75 \mu \mathrm{L}$, chloroform, methanol, and iodomethane were from EM Science (Gibbstown, NJ, USA), whereas glacial acetic acid was from Sigma. Acetonitrile was obtained from Fisher Scientific (Fair Lawn, NJ, 
Table 1. Summary of characteristic photofragment ions subjected to collisional dissociation

\begin{tabular}{|c|c|c|c|}
\hline$m / z$ & Precursor ion structures* & Fragments used for $\mathrm{MS}^{3}(\mathrm{~m} / \mathrm{z})$ & Structures associated with $\mathrm{MS}^{3}$ \\
\hline \multirow[t]{3}{*}{2153} & & 922 & \\
\hline & & 1167 & \\
\hline & & 1227,1412 & \\
\hline \multirow[t]{3}{*}{2071} & & - & - \\
\hline & & 895 & \\
\hline & & 1085 & \\
\hline \multirow[t]{3}{*}{1865} & & 676 & \\
\hline & & 1009 & ${ }^{2,4} \mathrm{~A}_{4}$ \\
\hline & & 885 & \\
\hline 2356 & & 922 & \\
\hline
\end{tabular}

USA). All water used in these experiments was purified by an E-pure water filtration system from Barnstead Thermolyne Co. (Dubuque, IA, USA).

\section{Enzymatic Release of $\mathrm{N}$-Glycans from Ovalbumin}

The enzymatic release of $\mathrm{N}$-glycans from ovalbumin was carried out according to our previously published proce- dure [51]. Briefly, $50 \mu \mathrm{g}$ glycoprotein was suspended in 25 $\mu \mathrm{L}$ of an incubation buffer consisting of $10 \mathrm{mM}$ sodium phosphate (pH 7.0) and 1\% mercaptoethanol. The sample was then thermally denatured by incubation at $95^{\circ} \mathrm{C}$ for 5 min. Next, it was allowed to cool to room temperature before the addition of $5 \mathrm{mU}$ of PNGase $\mathrm{F}$ and incubation at $37^{\circ} \mathrm{C}$ in a water bath overnight. Finally, the sample was dried under a stream of nitrogen before permethylation. 
Table 1. Continued

\begin{tabular}{ccc}
\hline$m / z$ & Fragments used for $\mathrm{MS}^{3}(\mathrm{~m} / \mathrm{z})$ & ${\text { Structures associated with } \mathrm{MS}^{3}}^{{ }^{2,4} \mathrm{~A}_{4}}$ \\
\hline \hline
\end{tabular}

*Refs. [59-63]

\section{Solid-Phase Permethylation}

All glycans were permethylated following our solidphase permethylation method [52]. First, a capillary reactor consisting of PEEK (polyetherether ketone polymer) tubing with 1-mm inner diameter (id) was connected to a PEEK union with a stainless steel frit. Sodium hydroxide beads suspended in acetonitrile were then used to pack the capillary reactor. Samples prepared in DMSO were infused through the reactor at a flow rate of $2 \mu \mathrm{L} / \mathrm{min}$. Typically, a $50 \mu \mathrm{g}$ sample aliquot was suspended in $30 \mu \mathrm{L}$ of DMSO, to which 0.3 $\mu \mathrm{L}$ of water and $5.6 \mu \mathrm{L}$ of methyl iodide were added. The permethylated glycans eluted from the sodium hydroxide reactor were subsequently extracted from the mixture with chloroform and washed repeatedly with cold water before evaporation.

\section{Sample Preparation}

The dried permethylated samples were resuspended in $25 \mu \mathrm{L}$ of 50/50 methanol/water solution containing 1 $\mathrm{mM}$ sodium acetate. Samples were infused directly into the mass spectrometer without any prior chromatographic separations at $300 \mathrm{~nL} / \mathrm{min}$, whereas the ESI capillary voltage was set to $1.8 \mathrm{kV}$.

\section{Instrumentation}

Electrospray experiments were performed on a Thermo Fisher linear quadrupole ion trap (LTQ) mass spectrometer (San Jose, CA, USA) equipped with an in-house fabricated nano-ESI source (75 $\mu \mathrm{m}$ id fused silica capillary pulled into a tip needle). The system was upgraded with LTQ 1.0 developer's Kit software and calibrated using PPG 2700 (for 2000-4000 Da region). All samples were infused into the LTQ mass spectrometer at flow rates ranging between 300 and $500 \mathrm{~nL} / \mathrm{min}$ using a syringe pump. The ion injection time was set to 500-1000 ms with an isolation width of 2-3 Da to select glycan precursor ions. Automatic gain control (AGC) was used to accumulate sufficient precursor ions (Full MS and MS $^{n}$ target value $1 \times 10^{5}$ ions). CID was accomplished using helium gas at a normalized collision energy of $30-50 \%$ for $60 \mathrm{~ms}$ (single scan) with a Q-value of 0.25 . A total of 60 microscans were averaged to produce a spectrum. The LTQ was also slightly modified to be compatible with $157 \mathrm{~nm}$ photodissociation, as recently reported $[48-50,53]$. Briefly, an $\mathrm{F}_{2}$ laser capable of $60-\mathrm{Hz}$ repetition rate (EX100HF-60, GAM Laser, Orlando, FL, USA), producing $2 \mathrm{~mJ}$ of light in a 10-ns pulse, was connected to the back of the LTQ instrument with a vacuum line. The unfocused light was introduced into the trap through a $1.7-\mathrm{mm}$ diameter aperture aligned with the preexisting 2-mm hole in the back lens of the LTQ. Based on the size of the aperture and the laser beam profile, we estimate that about $40 \mu \mathrm{J}$ of light passes into the ion trap. After irradiating the trapped ions, most of the light then passes through the hole in the front lens of the trap. The precursor ion isolation conditions were the same as those in CID experiments, except that the normalized collision energy was set to $0 \%$ at a Q-value of 0.10 . Since collision gas is not introduced into the analyzer cell it is possible to use a lower ion trap Q-value during photodissociation experiments $[54,55]$. The advantage of this, in principle, is that lower mass fragment ions should be detectable. The laser was triggered by the LTQ at the beginning of the activation stage. To pursue $\mathrm{MS}^{3}$ experiments, the signal intensities of $\mathrm{MS}^{2}$ fragment ions were enhanced by photodissociating with three laser shots. This significantly improves the signal intensities of $\mathrm{MS}^{2}$ photofragments. Once an ion of interest is selected for MS $^{3}$ experiments, $20-30 \%$ of normalized collision energy was used for further fragmentation. MS/MS interpretation was aided through the use of the Chem Draw Ultra 10 (Cambridge Soft, Cambridge, MA, USA).

An Applied Biosystems (Foster City, CA, USA) 4800 proteomics analyzer was used for high-energy $1 \mathrm{keV}$ CID experiments with argon collision gas at a pressure of $1 \times 10^{-7}$ Torr. MALDI spots were prepared by dissolving 10-20 pmol of the dried samples in $10 \mu \mathrm{L}$ of DHB matrix solution $(20 \mathrm{~g} / \mathrm{L})$ in 1:1 $\mathrm{vol} / \mathrm{vol} \mathrm{MeOH} /$ water containing $1 \mathrm{mM}$ sodium acetate. The acquired spectra were the average of 1000 laser shots. MS and 

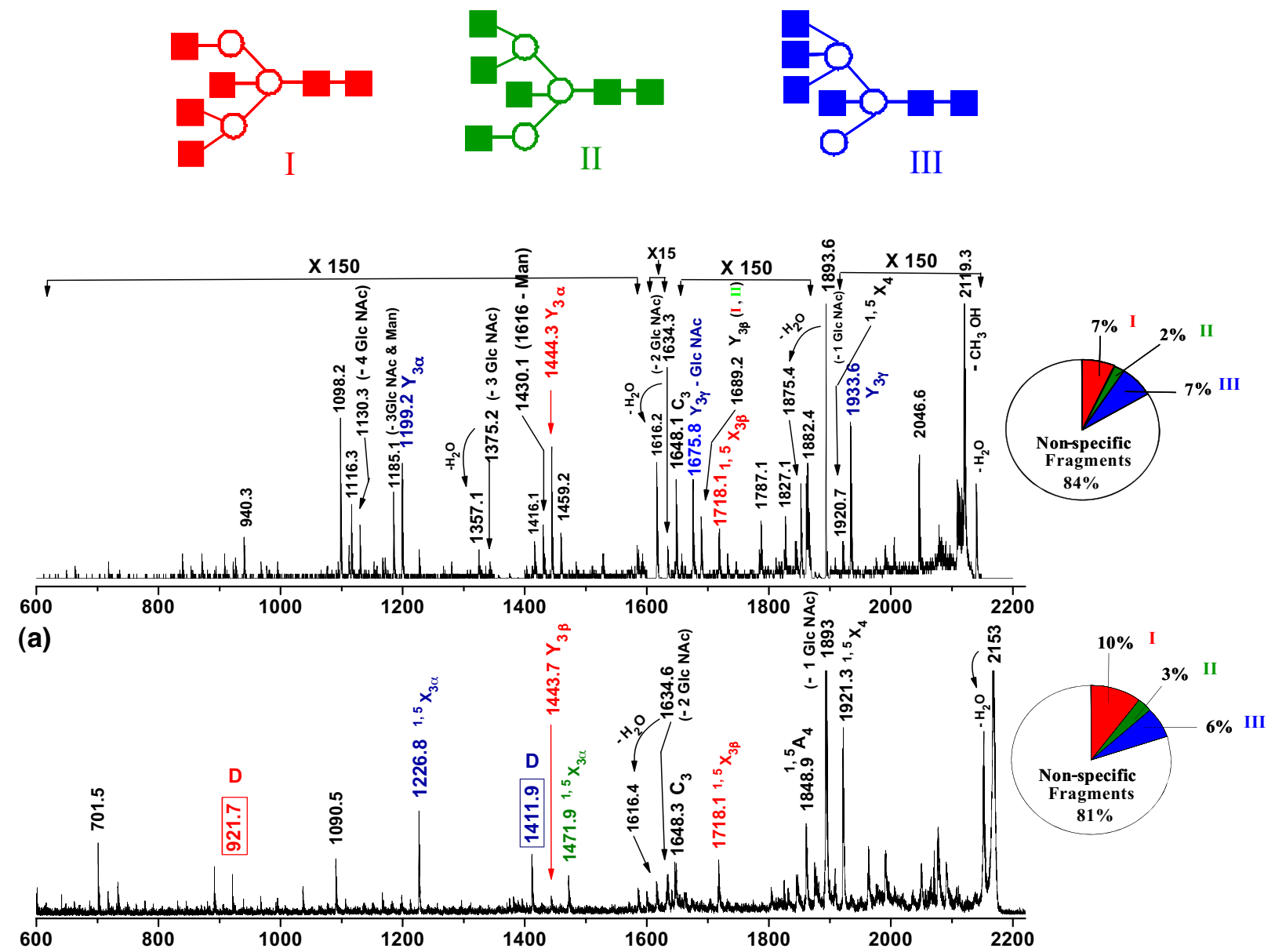

(b)

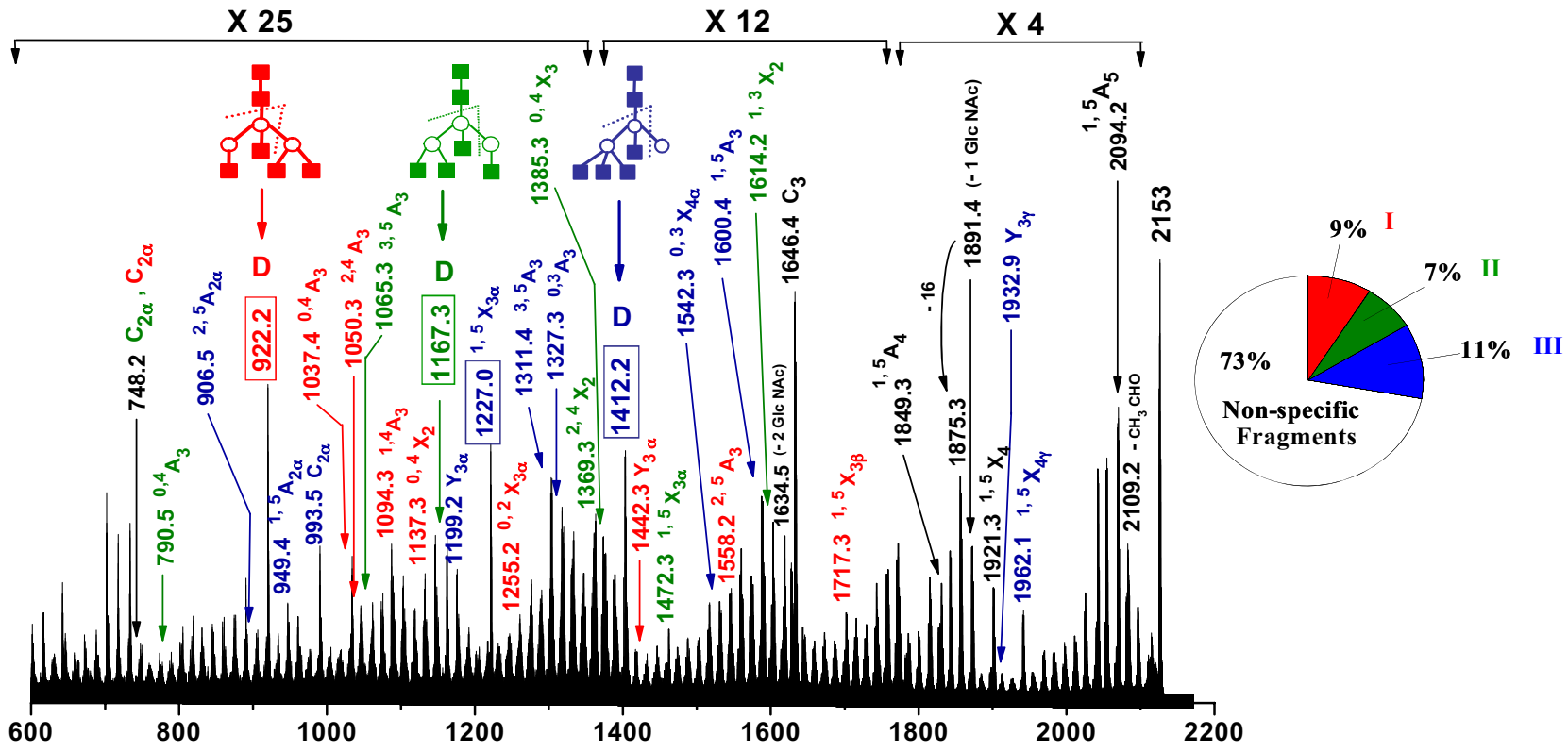

(c)

Figure 2. (a) $\mathrm{MS}^{2}$ fragmentation spectra of $[\mathrm{M}+\mathrm{Na}]^{+}$permethylated glycan precursor $\mathrm{m} / z 2153$ (from ovalbumin) obtained by (b) low-energy CID in ion trap, (c) high-energy CID in MALDI-TOF/ TOF, and (d) $157 \mathrm{~nm}$ photodissociation in ion trap. All fragments are observed as sodium adducts. The inset demonstrates the formation of key product ions (denoted in different colors) during fragmentation. Nonspecific product ions are labeled in black letters. Note changes in vertical scale within spectra. $\mathbf{\square} \rightarrow$ GlcNAc $\bigcirc \rightarrow$ Man $\bullet \rightarrow$ Gal. 


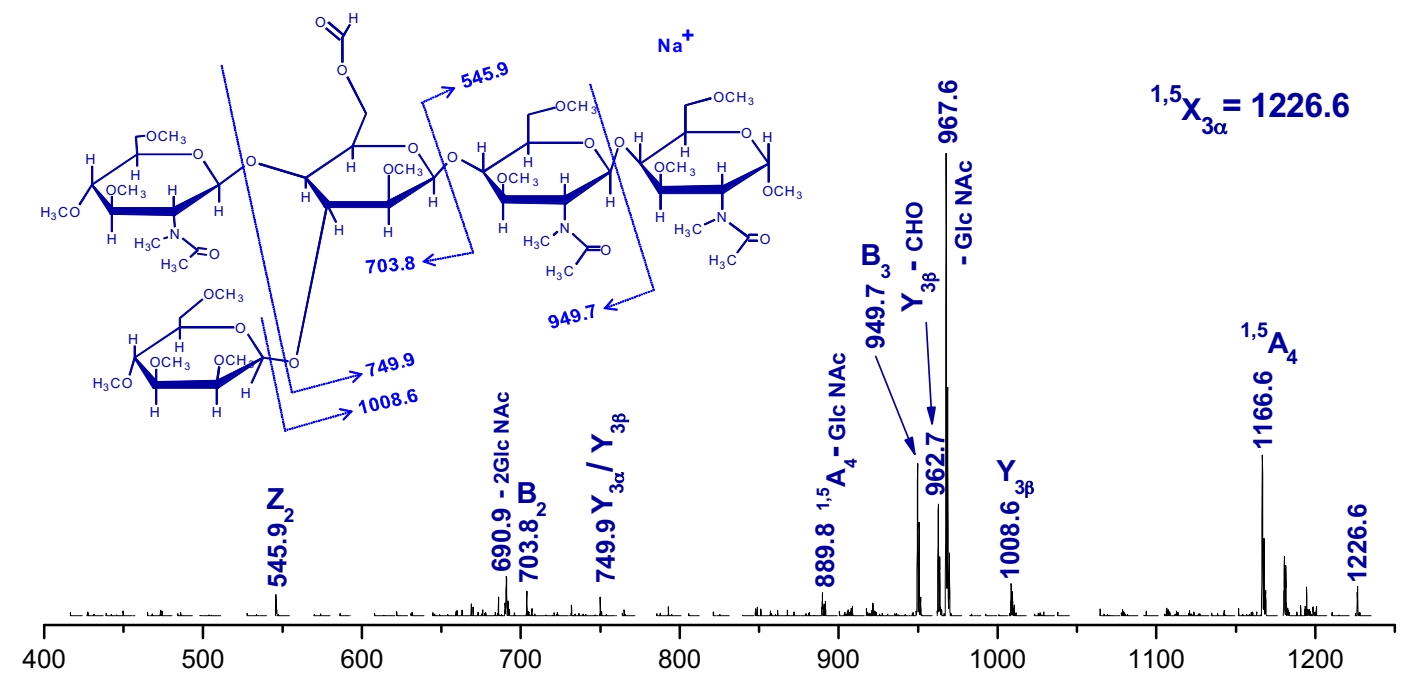

(a)

(b)
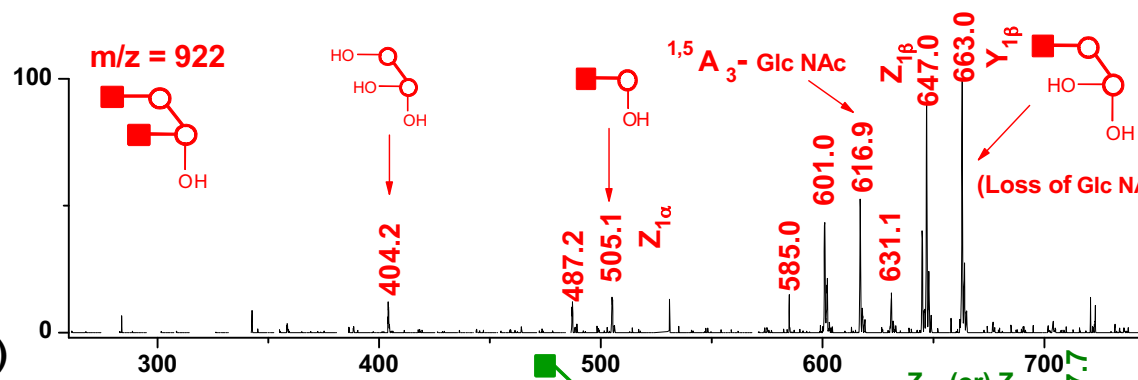

(c)

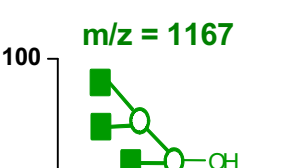

)
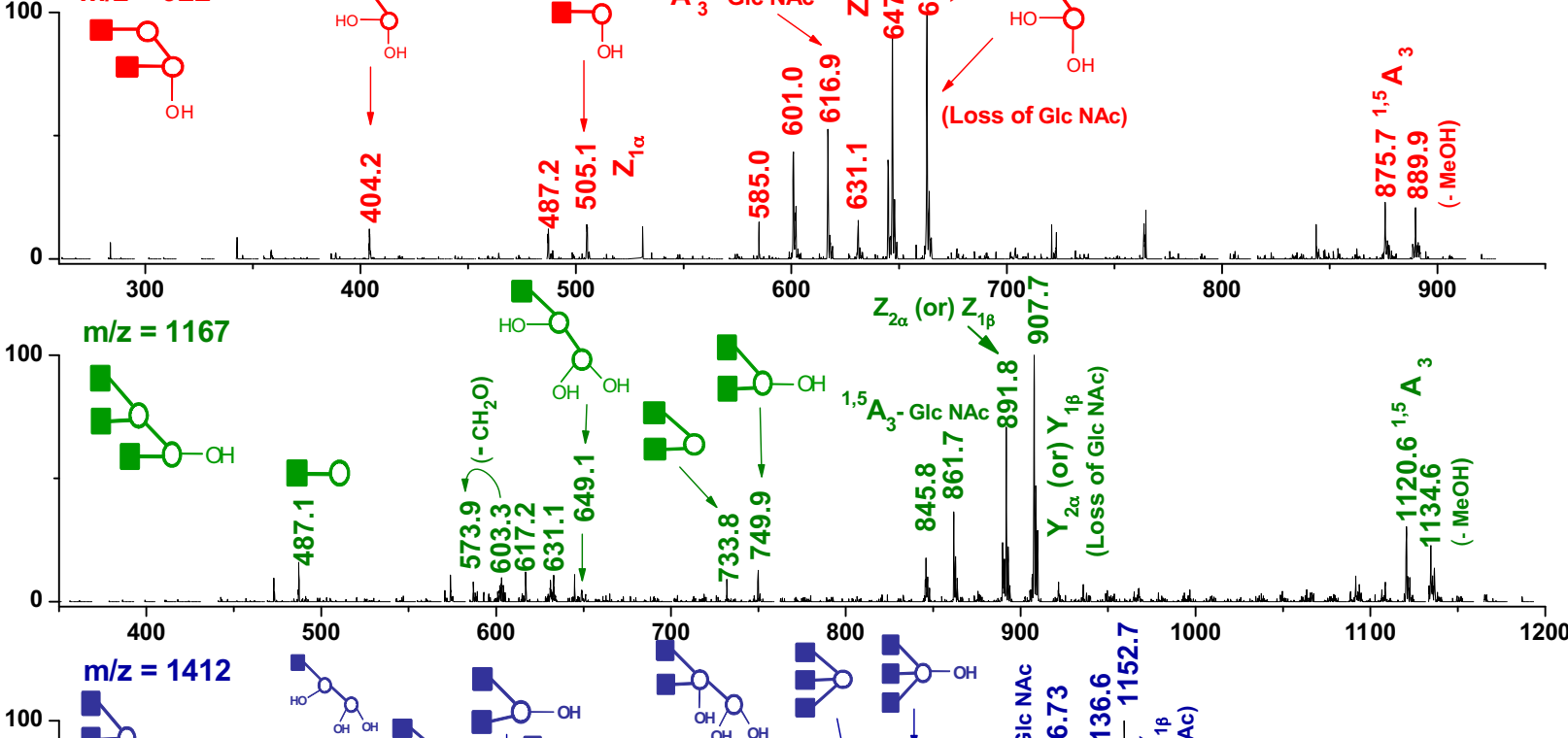

(d)

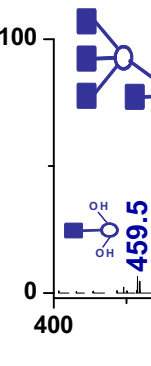

Figure 3. (a) $\mathrm{MS}^{3} \mathrm{CID}$ spectrum of the cross-ring photofragment $\mathrm{m} / z 1226$ obtained from $[\mathrm{M}+\mathrm{Na}]^{+}$ permethylated glycan precursor $\mathrm{m} / \mathrm{z} 2153$ after $157 \mathrm{~nm}$ photodissociation. MS ${ }^{3}$ CID spectra of photofragments $\mathrm{m} / \mathrm{z}$ (b) 922, (c) 1167, and (d) 1412 generated from ion $\mathrm{m} / \mathrm{z} 2153$. Ions generated from multiple cleavage sites are designated with a slash between the sites of cleavage. All fragments are observed as sodium adducts.

MS/MS data were further processed using Data Explorer 4.0 (Applied Biosystems).

\section{Results and Discussion}

It is common in any fragmentation technique to evaluate how effectively precursor ions are converted into fragments; this can be done by measuring the extent of precursor ion depletion caused by laser irradiation. The precursor ion depletion rate in our study was calculated as the difference between the precursor ion intensity before and after photofragmentation divided by the precursor ion intensity before photofragmentation. It was possible to achieve consistent results with this 

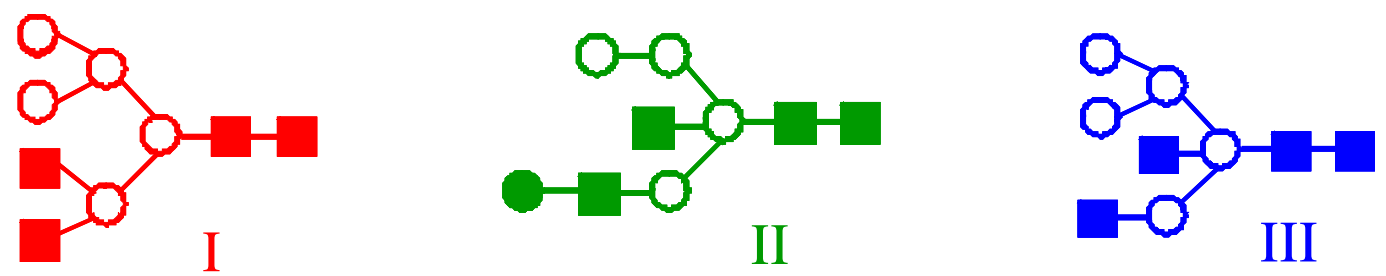

(a)

(b)

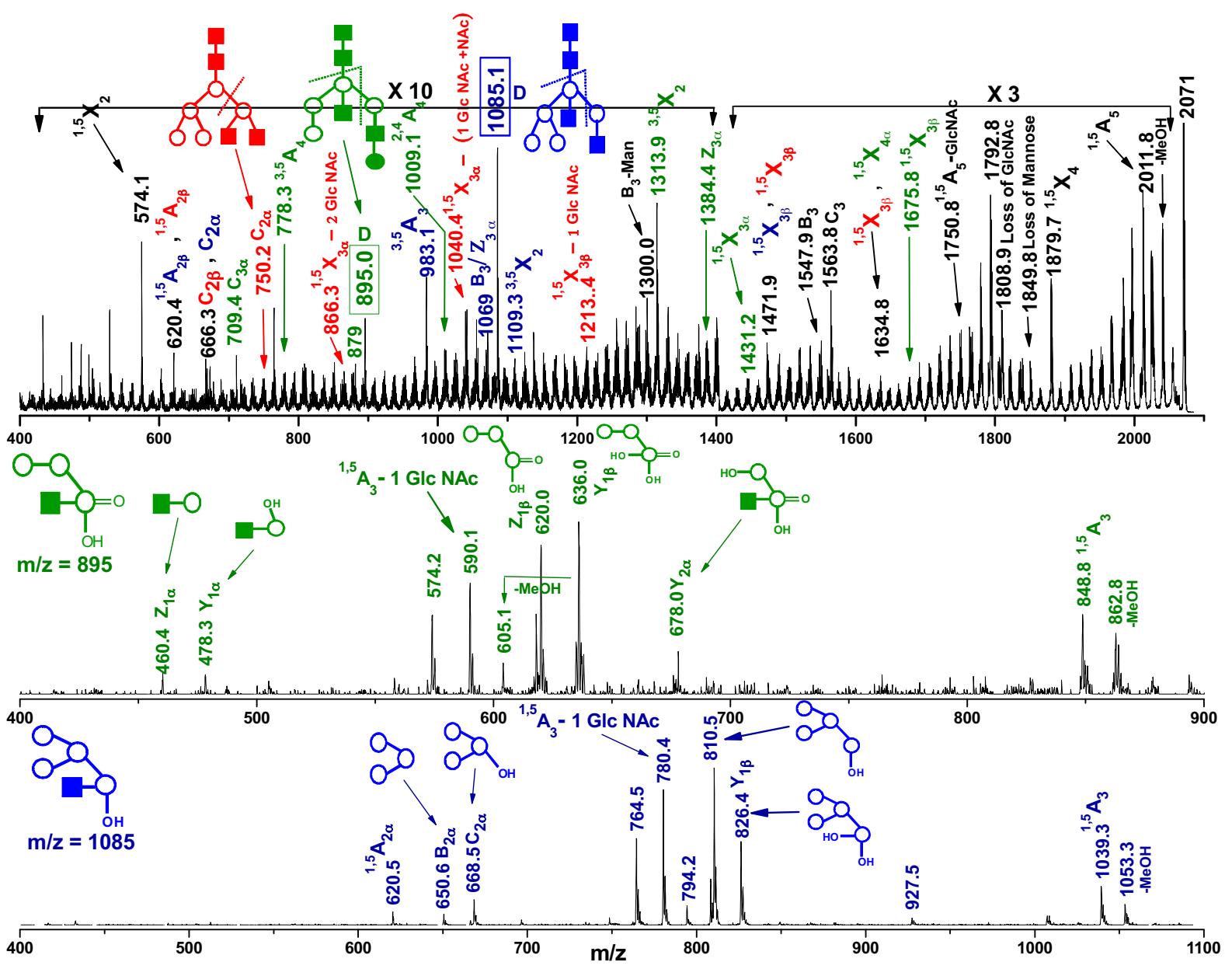

Figure 4. (a) $\mathrm{MS}^{2}$ photodissociation spectrum of $[\mathrm{M}+\mathrm{Na}]^{+}$permethylated glycan precursor $\mathrm{m} / \mathrm{z}$ 2071 (from ovalbumin). MS ${ }^{3}$ CID spectra of photofragments $\mathrm{m} / \mathrm{z}$ (b) 895 and (c) 1085 generated from ion $\mathrm{m} / \mathrm{z}$ 2071. Ions attributed to multiple cleavage sites are designated with a slash between the sites of cleavage. All fragments are odserved as sodium adducts. Note the changes in vertical scale within spectra.

method since the precursor ion signal intensities were stable to within about $3 \%$. In our previous published work, precursor ion depletion rates of approximately $25 \%$ have been measured for peptides [47] and linear oligosaccharides [49]. Recently, we applied $15 \%$ of the normalized collision energy during photodissociation experiments to increase the fragmentation efficiency. This significantly improves the signal intensities of $\mathrm{MS}^{2}$ stage photofragments [53]. It was of interest to study this efficiency using multiple laser shots that were employed to generate our photofragmentation spectra. Two ovalbumin glycans having $\mathrm{m} / \mathrm{z}$ values of 2070 and
2153 were chosen as models to perform this study. We found that more laser shots consistently yield greater product ion signals. In one case, about $90 \pm 3 \%$ precursor ion depletion was observed with three laser shots (Supplemental Figure S1, which can be found in the electronic version of this article). Typical experimental spectra obtained from the $\mathrm{m} / \mathrm{z} 2070$ ion with one to three laser shots are displayed in Figure 1a-c.

It is evident that additional laser shots do not change the types of photofragments formed but simply improve the $\mathrm{MS}^{n}$ signal. The intensities of the fragment ions generated using two laser shots (Figure 1b) were 

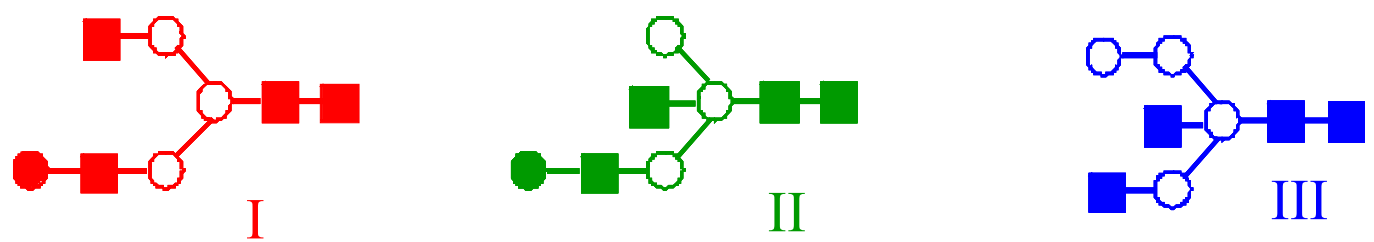

(a)

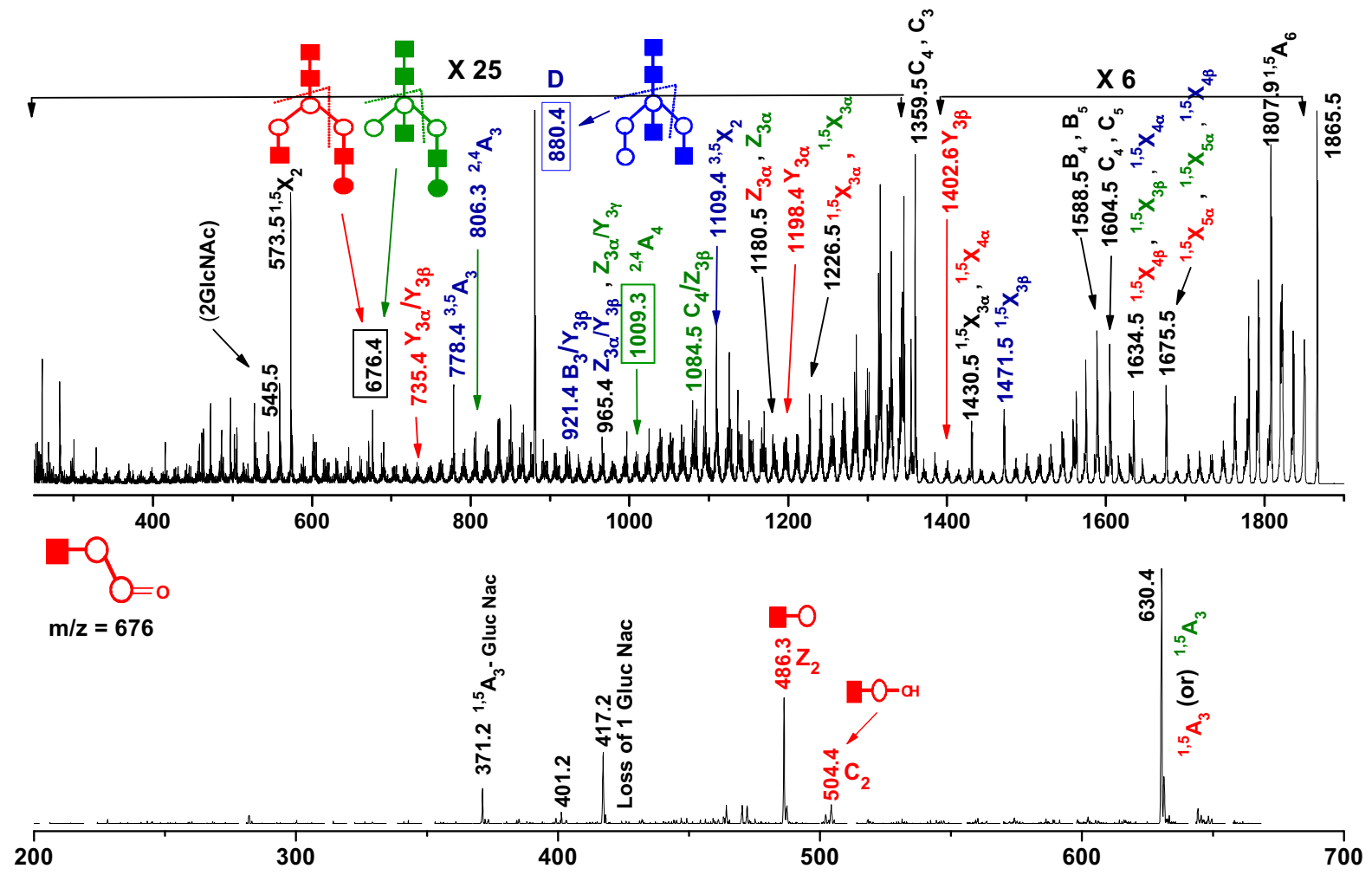

(b)

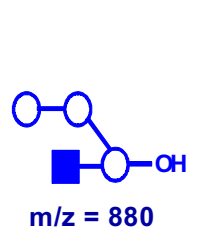

(c)
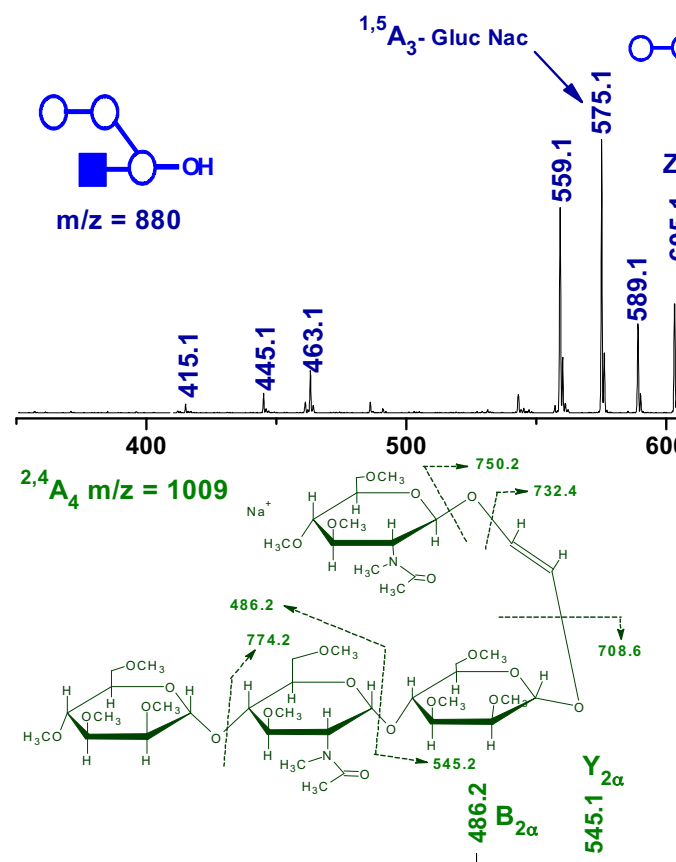

(d)

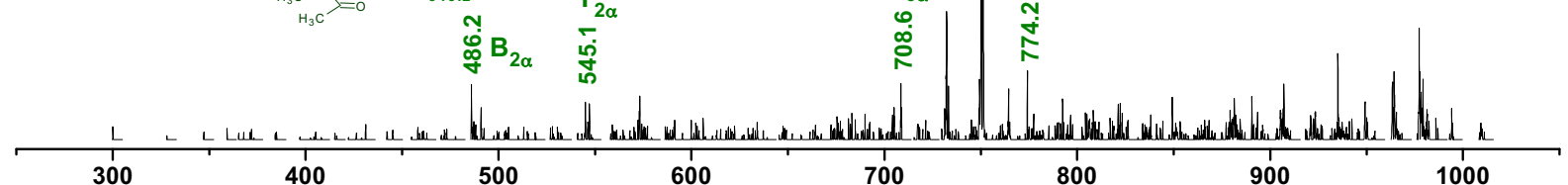


about threefold higher than those observed using a single laser shot (Figure 1a). Similarly, the intensities of the fragment ions resulting from three laser shots (Figure 1c) were about sixfold higher than those observed using a single shot. Therefore, three laser shots were used in subsequent experiments yielding cleaner spectra with better signal-to-noise $(\mathrm{S} / \mathrm{N})$ ratios. It is noteworthy that the present depletion rates are considerably higher than what we previously reported for linear charge-tagged oligosaccharides [49]. This could arise for a few reasons. First, there are more sugar rings in these branched molecules, leading to larger absorption coefficients. Second, the presence of N-acetyl groups in ovalbumin glycans and the permethylation of these structures could likewise provide additional absorption chromophores. Third, improved alignment of the $157 \mathrm{~nm}$ light with the axis of the ion trap may now lead to irradiation of more of the trapped ions.

The nomenclature introduced by Dommon and Costello [56], Spina et al. [57], and Stephens and colleagues [58] is used throughout this work to describe the fragmentation processes. Our recent work with permethylated acidic and neutral N-glycans demonstrated the ability to form abundant cross-ring fragments inside the ion trap with $157 \mathrm{~nm}$ light activation [50]. We also learned that singly charged ions yielded more informative spectra than their multiply charged counterparts and concluded that photodissociation produced high-energy fragmentation pathways $[49,50]$. In this report, we explore the capabilities of the ion-trap photodissociation combination for the structural characterization of permethylated $[\mathrm{M}+\mathrm{Na}]^{+}$isomeric $\mathrm{N}$-glycans derived from ovalbumin. Table 1 summarizes the masses and structures of different glycan isomers with some of their photofragment ions that are characterized in this study. The structures of these glycans have been studied over the last twenty years and were reported to be very heterogeneous [59-63]. The nano-ESI MS spectrum of the permethylated glycan mixture released from ovalbumin is in Supplemental Figure S2. To demonstrate the capability of photofragmentation, we specifically focused on glycans that contain at least three possible isomeric structures observed at masses of about 2000 Da. The low-energy CID spectrum displayed in Figure 2a was generated in the linear ion-trap instrument for the (GlcNAc) $)_{6}(\mathrm{Man})_{3}$ glycan structure $(\mathrm{m} / \mathrm{z} 2153)$. It was previously shown that this structure consists of three isomeric glycan structures (denoted in different colors) depicted as I, II, and III in the inset of Figure 2a [62, 63]. The most abundant product ion observed in the spectrum is $\mathrm{m} / \mathrm{z}$ 1894, corresponding to the facile loss of GlcNAc (N- acetyl glucosamine) residue from the precursor. A peak at $m / z 1648\left(C_{3}\right)$ belongs to the loss of two GlcNAc residues from the reducing end of the molecule. The formation of these nonspecific product ions (labeled in black letters) appears to be significantly limiting the yield of other product ions. Importantly, they can arise from any of the given isomeric structures and are not helpful either to identify or to distinguish the isomers. Minor ions at $m / z$ values of $1199\left(\mathrm{Y}_{3 \alpha}\right), 1676\left(\mathrm{Y}_{3 \gamma}-\right.$ GlcNAc), and $1933\left(\mathrm{Y}_{3 \gamma}\right)$ are indicative of isomer III (shown in blue). Other features at $m / z 1444\left(\mathrm{Y}_{3 \alpha}\right)$ and $1718\left({ }^{1,5} \mathrm{X}_{3 \beta}\right)$ point to the presence of isomer I (shown in red). Also present in Figure $2 \mathrm{a}$ is the ion at $\mathrm{m} / \mathrm{z} 1689$ $\left(\mathrm{Y}_{3 \beta}\right)$ that could be assigned to isomers I and II (shown in green). However, the signal intensities of all of these diagnostic fragments were low and the information was certainly not sufficient to distinguish all three isomeric structures. Thus the ion-trap $\mathrm{MS}^{2}$ analysis of these glycans would not be sufficient to reveal the presence of all of the isomeric structures of this $m / z$ value. Similar observations were made by Reinhold and co-workers [39]. The pie chart in Figure 2a displays the percentages of specific and nonspecific fragment ions. It is evident that the majority of low-energy CID fragments are nonspecific.

The same analyte was subjected to high-energy CID in MALDI-TOF/TOF and the resulting spectrum is shown in Figure 2b. Despite the strong signal upon isolation, the first MS/MS event did not completely fragment the precursor ion. The product ion at $m / z$ 922, formed by two glycosidic cleavages $B_{3} / Y_{3 \alpha}$ as depicted in the spectrum inset (usually denoted as D-ion) [64], is indicative of isomer I (red). Ions at $m / z 1444\left(\mathrm{Y}_{3 \beta}\right)$ and $1718\left({ }^{1,5} \mathrm{X}_{3 \beta}\right)$ also support the presence of isomer I. The product ion at $m / z 1472\left({ }^{1,5} X_{3 \alpha}\right)$ can be assigned to isomer II (green). Other fragment ions at $\mathrm{m} / \mathrm{z} 1227$ $\left({ }^{1,5} \mathrm{X}_{3 \alpha}\right)$ and 1412 (D-ion) in the spectrum point to structure III (blue). As shown in the pie chart more specific fragments for each of the three isomers were observed in this type of fragmentation. However, most of the fragment ions observed by high-energy CID were again nonspecific. Although the information obtained from these fragments is better than that from lowenergy CID (Figure 2a), they are not sufficient to thoroughly characterize all three isomers present in the mixture. Most important, further explorations of these ions through $\mathrm{MS}^{3}$ experiments are not possible by this technique.

The analogous ion-trap $157 \mathrm{~nm}$ photodissociation spectrum of $m / z 2153$ ion, obtained by three laser shots, is presented in Figure 2c. Most strikingly, there is a dramatic increase in the number of fragment ions

Figure 5. (a) $\mathrm{MS}^{2}$ photodissociation spectrum of $[\mathrm{M}+\mathrm{Na}]^{+}$permethylated glycan precursor $\mathrm{m} / \mathrm{z}$ 1865 (from ovalbumin). MS ${ }^{3}$ CID spectra of photofragments $m / z$ (b) 676, (c) 880, and (d) 1009 generated from ion $\mathrm{m} / \mathrm{z}$ 1865. Ions attributed to multiple cleavage sites are designated with a slash between the sites of cleavage. All fragments are observed as sodium adducts. Note the changes in vertical scale within spectra. 

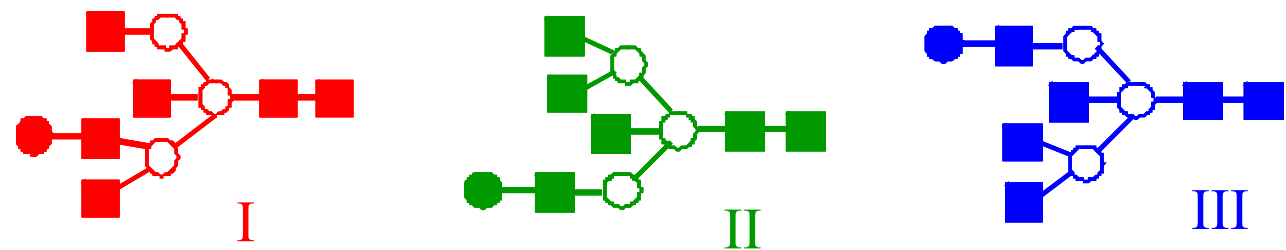

(a)
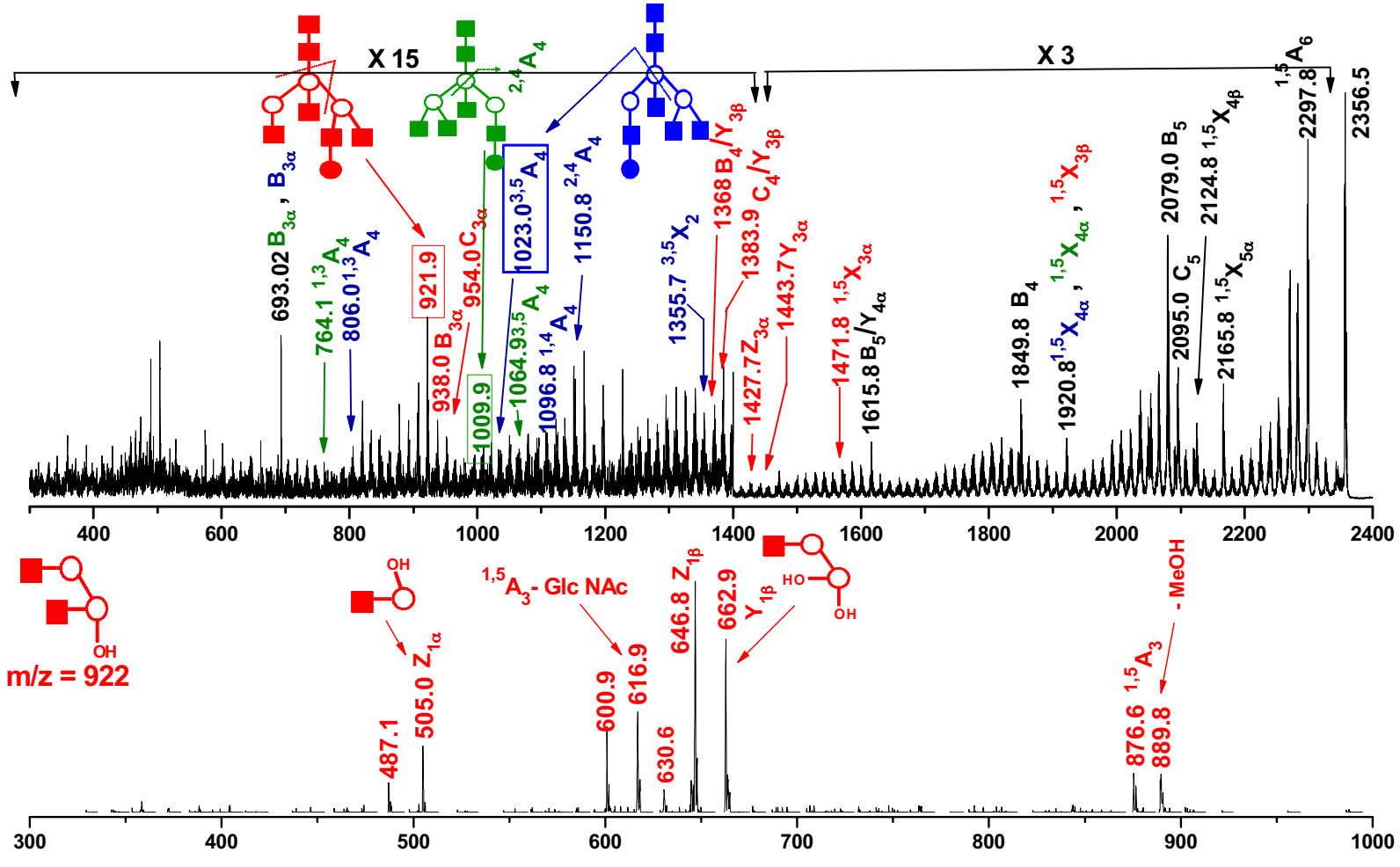

(b)

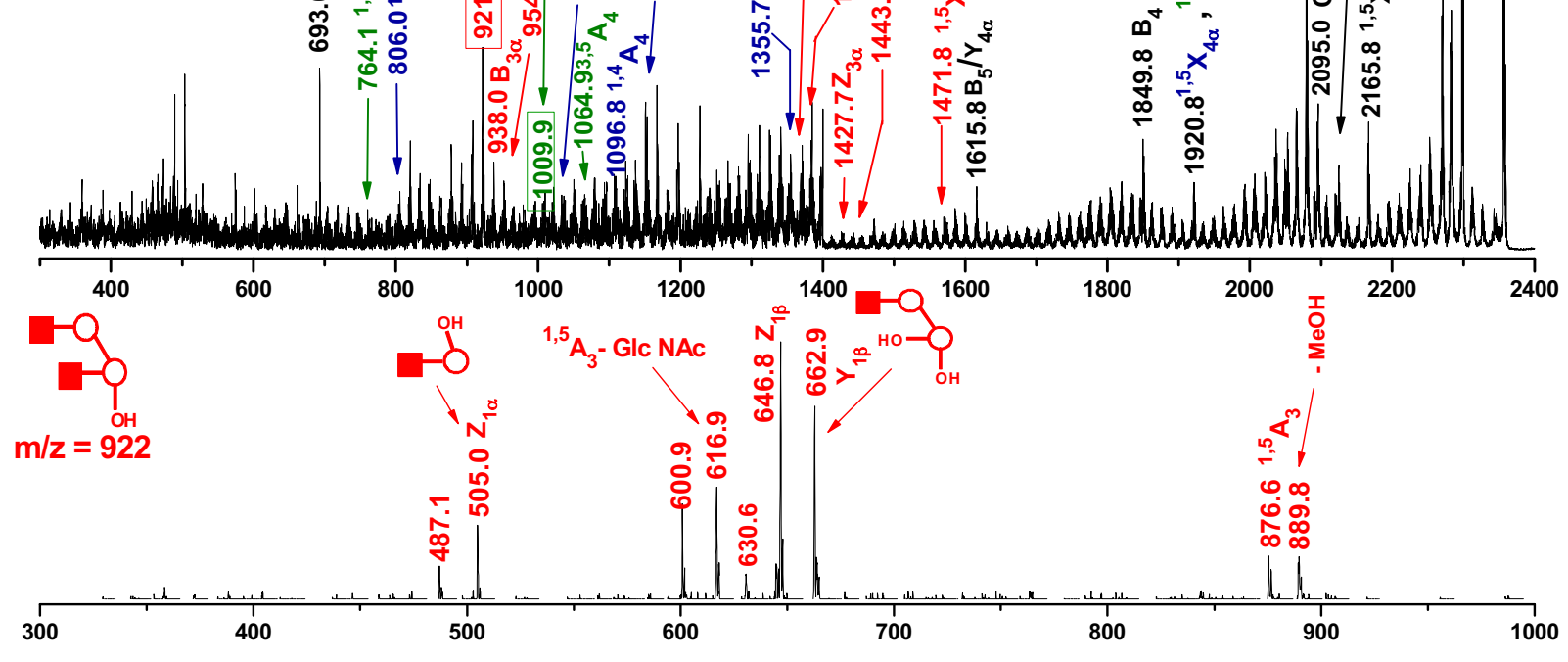

c)

${ }^{2,4} \mathrm{~A}_{4} \mathrm{~m} / \mathrm{z}=1010$

(c)

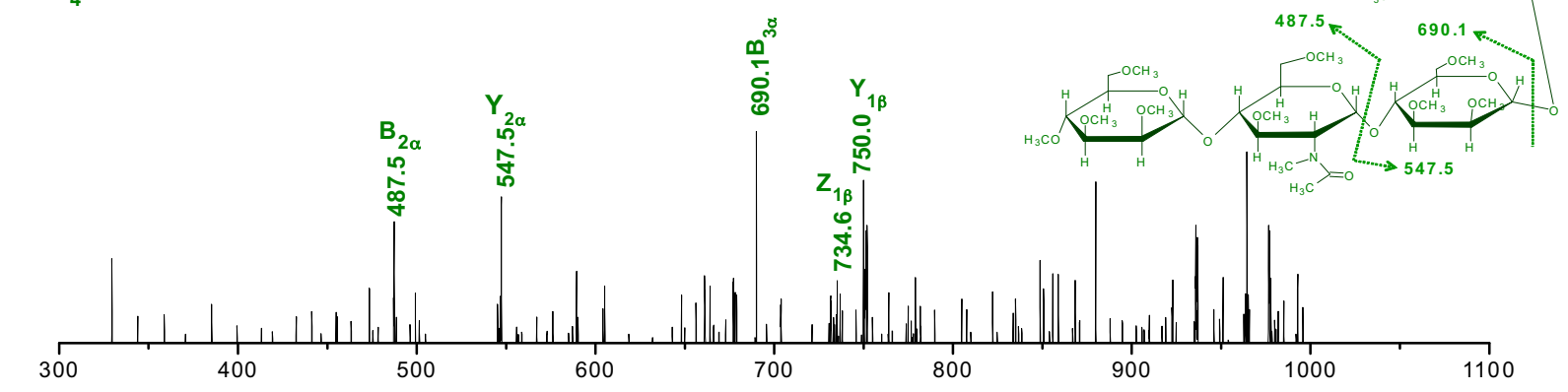

${ }^{3,5} A_{4} \mathrm{~m} / \mathrm{z}=1023$

(d) 
distributed evenly across the mass range. Extensive cross-ring fragment ions appear along with characteristic features that provide critical information about the existence of the three isomers. Ions observed at $\mathrm{m} / \mathrm{z}$ values of $922(\mathrm{D}), 1037\left({ }^{0,4} \mathrm{~A}_{3}\right), 1050\left({ }^{2,4} \mathrm{~A}_{3}\right), 1094\left({ }^{1,4} \mathrm{~A}_{3}\right)$, $1137\left({ }^{0,4} \mathrm{X}_{2}\right), 1255\left({ }^{0,2} \mathrm{X}_{3 \alpha}\right), 1442\left(\mathrm{Y}_{3 \alpha}\right), 1558\left({ }^{2,5} \mathrm{~A}_{3}\right)$, and $1717\left({ }^{1,5} X_{3 \beta}\right)$ were consistent with structure I (red), whereas ions observed at $m / z$ values of $790\left({ }^{0,4} \mathrm{~A}_{3}\right), 1065$ $\left({ }^{3,5} \mathrm{~A}_{3}\right), 1167$ (D), $1369\left({ }^{2,4} \mathrm{X}_{2}\right), 1385\left({ }^{0,4} \mathrm{X}_{3}\right), 1472\left({ }^{1,5} \mathrm{X}_{3 \alpha}\right)$, and $1614\left({ }^{1,3} X_{2}\right)$ account for isomer II (green). Ions originating from isomer III (blue) include those observed at $m / z$ values of $906.5\left({ }^{2,5} \mathrm{~A}_{2 \alpha}\right), 949\left({ }^{1,5} \mathrm{~A}_{2 \alpha}\right), 993.5$ $\left(C_{2 \alpha}\right), 1199\left(Y_{3 \alpha}\right), 1227\left({ }^{1,5} \mathrm{X}_{3 \alpha}\right), 1311\left({ }^{3,5} \mathrm{~A}_{3}\right), 1327\left({ }^{0,3} \mathrm{~A}_{3}\right)$, $1412(\mathrm{D}), 1542\left({ }^{0,3} \mathrm{X}_{4 \alpha}\right), 1600\left({ }^{1,5} \mathrm{~A}_{3}\right), 1933\left(\mathrm{Y}_{3 \gamma}\right)$, and $1962\left({ }^{1,5} \mathrm{X}_{4 \gamma}\right)$. Accordingly, these unique features in the $\mathrm{MS}^{2}$ experiments permit the three isobaric structures to be distinguished. As indicated in its pie chart, photofragmentation appears to generate more specific fragment ions for the three isomers relative to the other techniques. This being said, fragmentation in general is dependent on the structure; therefore, the percentages observed in Figure 2 could easily vary for different structures.

Although several other peaks appear in the spectrum, they do not provide adequate information about the structural isomers. In particular, the distribution of numerous intense high mass photofragments separated by 14 and 16 Daltons is common to all photofragmentation spectra. We believe that these product ions originate from a series of facile losses of small neutral molecules. To identify these molecules we are currently studying the photofragmentation of the chitobiose core and this will be the subject of a future publication.

A major advantage of the ion-trap mass spectrometer is the ability to perform $\mathrm{MS}^{n}$ CID experiments on any of the fragments including cross-ring product ions generated by photodissociation to confirm their identities. An example of this was obtained by the collisional activation of a cross-ring photofragment ion observed at $\mathrm{m} / \mathrm{z}$ $1227\left({ }^{1,5} \mathrm{X}_{3 \alpha}\right)$ originating from isomer III. The spectrum along with the structure and assignments of the fragments observed are displayed in Figure 3a. The detection of ions at $\mathrm{m} / \mathrm{z}$ values of $1008.6\left(\mathrm{Y}_{3 \beta}\right), 949\left(\mathrm{~B}_{3}\right), 704$ $\left(B_{2}\right)$, and $546\left(Z_{2}\right)$ allowed the assignment of the ${ }^{1,5} X_{3 \alpha}$ cross-ring fragment ion and its structure is presented in the spectrum inset.

The most important features at $m / z$ 922, 1167, and 1412 in the $\mathrm{MS}^{2}$ photofragmentation spectrum (Figure 2c) are $\mathrm{D}$ ions that result from two glycosidic cleavages. They are attributable to structures I, II, and III, respectively. Although there are higher mass fragments that are more abundant in the photofragmentation spectrum, they are not unique to specific isomers. Therefore subjecting these ions to high-order tandem MS experiments does not provide the needed information to unambiguously discriminate among the different glycan isomers. In contrast, D-type photofragment ions that have lost the core GlcNAc residues and the 3antenna are unique to each isomeric form and their identities can be confirmed by one stage of collisional fragmentation. To investigate the D-ion structures, the $m / z 922$ photofragment ion was selected for $\mathrm{MS}^{3} \mathrm{CID}$ analysis and the resulting spectrum is presented in Figure $3 \mathrm{~b}$. Appearance of fragment ions at $m / z$ values of 404,505 , and 663 could come only from isomer I. Similarly, $\mathrm{MS}^{3}$ experiments with photofragment ions $m / z 1167$ and 1412 are illustrated in Figure 3c and d, respectively. The most informative ions at $m / z$ values of 908, 750, and 734 in Figure 3c and 1153, 995, 977, and 894 in Figure 3d provide strong evidence for structures II and III, respectively. It is noteworthy that all the isomers were conclusively assigned in $\mathrm{MS}^{3}$ experiments.

Figure $4 \mathrm{a}$ is the $\mathrm{MS}^{2}$ photodissociation spectrum of the precursor ion at $\mathrm{m} / \mathrm{z} 2071$ [composition, (GlcNAc) $(\mathrm{Man})_{5}$ and $\left.(\mathrm{GlcNAc})_{4}(\mathrm{Man})_{4}(\mathrm{Gal})_{1}\right]$ derived from the permethylated ovalbumin glycan sample. The observed fragmentation pattern contains a variety of diagnostic fragment ions, suggesting the presence of three isomers: I (Red), II (Green), and III (blue) as depicted in the inset of Figure 4. This is in agreement with the structures previously reported [62]. Ions at $m / z$ values of 709,778 , $879,895,1009,1314,1384,1431$, and 1676, which originate from structure II (Green), correspond to $\mathrm{C}_{3 \alpha},{ }^{3,5} \mathrm{~A}_{4}$, $\mathrm{B}_{4} / \mathrm{Y}_{3 \alpha}, \mathrm{C}_{4} / \mathrm{Y}_{3 \alpha^{\prime}}{ }^{2,4} \mathrm{~A}_{4},{ }^{3,5} \mathrm{X}_{2}, \mathrm{Z}_{3 \alpha^{\prime}}{ }^{1,5} \mathrm{X}_{3 \alpha^{\prime}}$ and ${ }^{1,5} \mathrm{X}_{3 \beta}$, respectively. Photofragmentation of isomer III (blue) generates ions at $m / z$ values of $983\left({ }^{3,5} \mathrm{~A}_{3}\right), 1069\left(\mathrm{~B}_{3} / \mathrm{Z}_{3 \alpha}\right)$, $1085\left(C_{3} / Z_{3 \alpha}\right)$, and $1109\left({ }^{3,5} \mathrm{X}_{2}\right)$. The low-abundance fragment ions at $m / z$ values of $750\left(C_{2 \alpha}\right), 866\left({ }^{1,5} X_{3 \alpha}-\right.$ 2GlcNAc), $1040\left({ }^{1,5} \mathrm{X}_{3 \alpha}-1 \mathrm{GlcNAc}\right.$ and $\mathrm{N}$-acetyl group), and $1213\left({ }^{1,5} \mathrm{X}_{3 \beta}-1 \mathrm{GlcNAc}\right)$ detected in the photofragmentation spectrum were consistent only with isomer I. Other peaks at $m / z 620\left({ }^{1,5} \mathrm{~A}_{2 \beta}\right), 666\left(\mathrm{C}_{2 \alpha}, \mathrm{C}_{2 \beta}\right)$, and 1472 $\left({ }^{1,5} X_{3 \beta}\right)$ were supporting the presence of isomers II and III. Unfortunately, compared with isomers II and III, the diagnostic product ions from structure I were not sufficiently intense to perform $\mathrm{MS}^{3}$ experiments. However, the presence of structure I is conclusive from the presence of the above-mentioned ions. On the other hand, to validate that photofragment ions $\mathrm{m} / \mathrm{z} 895$ $\left(\mathrm{C}_{4} / \mathrm{Y}_{3 \alpha}\right)$ and $\mathrm{m} / \mathrm{z} 1085\left(\mathrm{C}_{3} / \mathrm{Z}_{3 \alpha}\right)$ originate from structures II and III, respectively, they were isolated and collisionally dissociated in the trap. The resulting $\mathrm{MS}^{3}$ spectra are depicted in Figure $4 \mathrm{~b}$ and c. The fragmentation pattern observed in the spectrum depicted in Figure $4 \mathrm{~b}$ provides strong evidence for the presence of

Figure 6. (a) $\mathrm{MS}^{2}$ photodissociation spectrum of $[\mathrm{M}+\mathrm{Na}]^{+}$permethylated glycan precursor $\mathrm{m} / \mathrm{z} 2356$ (from ovalbumin). MS ${ }^{3}$ CID spectra of photofragments $\mathrm{m} / z$ (b) 921, (c) 1009, and (d) 1023 generated from ion $\mathrm{m} / \mathrm{z}$ 2356. Ions attributed to multiple cleavage sites are designated with a slash between the sites of cleavage. All fragments are observed as sodium adducts. Note the changes in vertical scale within spectra. 
isomer II. Specifically, strong features at $m / z$ values of $678\left(\mathrm{Y}_{2 \alpha}\right), 636\left(\mathrm{Y}_{1 \beta}\right)$, and $620\left(\mathrm{Z}_{1 \beta}\right)$ could originate only from structure II. Similarly, the most intense fragment ions at $m / z 826\left(\mathrm{Y}_{1 \beta}\right), 810\left(\mathrm{Z}_{1 \beta}\right), 668.5\left(\mathrm{C}_{2 \alpha}\right)$, and 650.6 $\left(\mathrm{B}_{2 \alpha}\right)$ in Figure $4 \mathrm{c}$ are all consistent with the III structure and could not arise from the others.

Next, we photofragmented the ion at $m / z 1865$ that could be associated with three possible isomeric structures containing $(\mathrm{GlcNAc})_{4}(\mathrm{Man})_{4}$ and $(\mathrm{GlcNAc})_{4}$ $(\mathrm{Man})_{3}(\mathrm{Gal})_{1}$. The resulting photofragmentation MS/MS spectrum is shown in Figure 5a, and the structures of the three isomers are depicted in the inset. Again, a significant number of diagnostic product ions appears in this $\mathrm{MS}^{2}$ spectrum that provide valuable information about the existence of the different isomers associated with this glycan. Fragment ions at $m / z$ values of $735\left(\mathrm{Y}_{3 \alpha} / \mathrm{Y}_{3 \beta}\right), 1198\left(\mathrm{Y}_{3 \alpha}\right)$, and $1403\left(\mathrm{Y}_{3 \beta}\right)$ result from isomer I (Red). Ions at $m / z$ values of $1009\left({ }^{2,4} \mathrm{~A}_{4}\right)$ and $1084.5\left(\mathrm{C}_{4} / \mathrm{Z}_{3 \beta}\right)$ indicate the presence of structure II (Green). Other ions at $m / z$ values of $778\left({ }^{3,5} \mathrm{~A}_{3}\right), 806$ $\left({ }^{2,4} \mathrm{~A}_{3}\right), 880\left(\mathrm{Z}_{3 \alpha} / \mathrm{C}_{3}\right.$ or $\left.\mathrm{D}\right), 921\left(\mathrm{~B}_{3} / \mathrm{Y}_{3 \beta}\right), 1109\left({ }^{3,5} \mathrm{X}_{2}\right)$, and $1471\left({ }^{1,5} \mathrm{X}_{3 \beta}\right)$ point to isomer III (Blue). Also detected in Figure $5 \mathrm{a}$ are the ions at $\mathrm{m} / \mathrm{z}$ values of 676 (D), 1180 $\left(Z_{3 \alpha}\right)$, and $1226\left({ }^{1,5} X_{3 \alpha}\right)$ that are consistent with both I and II isomers. The peak at $m / z 965\left(Z_{3 \alpha} / Y_{3 \beta}, Z_{3 \alpha} / Y_{3 \gamma}\right)$ could be associated with structures II and III.

To further confirm the structures of these isomers $\mathrm{MS}^{3}$ experiments were performed on $\mathrm{m} / z 676$ (D), 880 (D), and $1009\left({ }^{2,4} \mathrm{~A}_{4}\right)$. Figure $5 \mathrm{~b}$ was generated by the collisional activation of the diagnostic photofragment $\mathrm{m} / \mathrm{z} 676$ that appeared to be a mixture of isomers I and II. However, the presence of two features at $m / z 504\left(C_{2}\right)$ and $486\left(\mathrm{Z}_{2}\right)$ confirmed the presence of isomeric structure I. Figure $5 \mathrm{c}$ presents an $\mathrm{MS}^{3} \mathrm{CID}$ spectrum of the photofragment ion observed at $m / z$ 880. Unique features at $m / z 662\left(\mathrm{Y}_{2 \alpha}\right), 621\left(\mathrm{Y}_{1 \beta}\right)$, and $605\left(\mathrm{Z}_{1 \beta}\right)$ are very helpful in identifying isomer III. Most noteworthy, these fragment ions enabled us to distinguish structure III from structures I and II. In the collisional dissociation of the photofragment observed at $m / z 1009\left({ }^{2,4} \mathrm{~A}_{4}\right)$, Figure 5d, we see diagnostic fragments such as $m / z 774\left(\mathrm{Y}_{3 \alpha}\right), 750$ $\left(\mathrm{Y}_{1 \beta}\right), 732\left(\mathrm{Z}_{1 \beta}\right)$, and $709\left(\mathrm{C}_{3 \alpha}\right)$ that provide valuable information to successfully assign the cross-ring fragment ion structure ${ }^{2,4} \mathrm{~A}_{4}$ corresponding to isomer II. In summary, $\mathrm{MS}^{2}$ and $\mathrm{MS}^{3}$ analysis of these structures conclusively assigns all isomers.

The effectiveness of photofragmentation in the structural characterization of glycans is also illustrated for the hybrid glycan consisting of (GlcNAc) ${ }_{6}(\mathrm{Man})_{3}(\mathrm{Gal})$, which generates singly charged ions at $\mathrm{m} / \mathrm{z} 2356$. The laser-induced MS/MS spectrum of this precursor ion is shown in Figure 6a. The observed fragmentation pattern is indicative of three possible isomers that are similar to those previously reported [62]. Although photodissociation provides informative $\mathrm{MS}^{2}$ fragment ions, the overall $\mathrm{S} / \mathrm{N}$ ratio of the spectrum is noticeably lower than that of the other examples discussed here, thus limiting our ability to perform high-order tandem MS experiments. The lower $\mathrm{S} / \mathrm{N}$ ratio is associated with the formation of multiply charged precursor ions by electrospray ionization, which significantly limits the abundance of the singly charged precursors. Nevertheless, it is interesting to note in Figure 6a that a variety of characteristic fragment ions provide important information regarding three isomeric structures, including ions at $m / z$ values of $922\left(\mathrm{C}_{4} / \mathrm{Z}_{3 \alpha}\right), 938\left(\mathrm{~B}_{3 \alpha}\right), 954\left(\mathrm{C}_{3 \alpha}\right), 1368$ $\left(\mathrm{B}_{4} / \mathrm{Y}_{3 \beta}\right), 1384\left(\mathrm{C}_{4} / \mathrm{Y}_{3 \beta}\right), 1428\left(\mathrm{Z}_{3 \alpha}\right), 1444\left(\mathrm{Y}_{3 \alpha}\right)$, and 1472 $\left({ }^{1,5} X_{3 \alpha}\right)$, reflecting the presence of isomer I (Red). The structure of isomer II (Green) is supported by the appearance of diagnostic cross-ring fragment ions at $m / z$ values of $764\left({ }^{1,3} \mathrm{~A}_{4}\right), 1010\left({ }^{2,4} \mathrm{~A}_{4}\right)$, and $1065\left({ }^{3,5} \mathrm{~A}_{4}\right)$. Also present in Figure $6 \mathrm{a}$ are the features at $m / z$ values of $806\left({ }^{1,3} \mathrm{~A}_{4}\right), 1023\left({ }^{3,5} \mathrm{~A}_{4}\right), 1097\left({ }^{1,4} \mathrm{~A}_{4}\right), 1151\left({ }^{2,4} \mathrm{~A}_{4}\right)$, and $1356\left({ }^{3,5} X_{2}\right)$ that reveal the existence of isomeric structure III (Blue). To further confirm, we isolated certain specific photofragments and collisionally dissociated them inside the trap. The $\mathrm{MS}^{3}$ spectrum of the photofragment observed at $m / z 922$ (D ion, $\mathrm{C}_{4} / \mathrm{Z}_{3 \alpha}$ ) is displayed in Figure $6 \mathrm{~b}$. The most important and intense fragment ions at $m / z 663\left(\mathrm{Y}_{1 \beta}\right), 647\left(\mathrm{Z}_{1 \beta}\right)$, and $505\left(\mathrm{Z}_{1 \alpha}\right)$ in the spectrum provide strong evidence for the isomeric structure I. Similarly, collisional dissociation of photofragment ion $\mathrm{m} / \mathrm{z} 1010$ yields the spectrum in Figure 6c. Despite the low $\mathrm{S} / \mathrm{N}$ ratio, this spectrum contains valuable product ions at $m / z 750\left(\mathrm{Y}_{1 \beta}\right), 690$ $\left(\mathrm{B}_{3 \alpha}\right), 548\left(\mathrm{Y}_{2 \alpha}\right)$, and $488\left(\mathrm{~B}_{3 \alpha}\right)$, pointing to the presence of structure II. The $\mathrm{MS}^{3}$ spectrum depicted in Figure $6 \mathrm{~d}$ was obtained from photofragment ion $m / z 1023\left({ }^{3,5} \mathrm{~A}_{4}\right)$. It contains low-abundance product ions at $m / z 788\left(\mathrm{Z}_{2 \alpha}\right)$, $765\left(\mathrm{Y}_{1 \beta}\right), 749\left(\mathrm{Z}_{1 \beta}\right)$, and $487\left(\mathrm{~B}_{2 \alpha}\right)$, consistent with isomer III.

\section{Summary and Conclusions}

Several examples of indigenous isomeric ovalbumin glycan structures could be identified from $\mathrm{MS}^{2}$ spectra alone. The ion-trap $\mathrm{MS}^{3}$ experiments allow us to isolate diagnostic photofragments including cross-ring fragment ions and confirm the individual isomeric structures present in the mixture without prior chromatographic separation. Furthermore, these experiments confirmed that the product ions observed with photodissociation are similar to those generated during highenergy CID methods. Here, we demonstrated the ability to isolate and collisionally activate ions generated through photofragmentation. A challenging aspect, however, is to understand the distribution of product ions that are separated by 14 and 16 Daltons throughout the photodissociation spectra. These are currently under investigation.

In this work, we demonstrated the analytical merits of $157 \mathrm{~nm}$ photofragmentation to characterize the isomeric structures of high-mass N-glycans from ovalbumin. Photodissociation yielded numerous product ions including extensive cross-ring fragment ions of analytical value such as those distinguishing between isomeric N-glycan structures. Another major advantage exploited in this study is the ability to perform $\mathrm{MS}^{n} \mathrm{CID}$ 
experiments on the characteristic fragments generated by photodissociation. The presence of individual isomers in a glycoform was confirmed in $\mathrm{MS}^{3}$ experiments. However, as mass increases the number of singly charged ions generated by electrospray ionization drops. This makes high-order $\mathrm{MS}^{n}$ experiments on high-mass ions more difficult. This problem could be addressed if MALDI ionization sources are coupled to the LTQ mass spectrometer. Currently, experiments with multiply charged ions to investigate the influence of charge state on glycan photodissociation are also being pursued. It will be interesting to perform photodissociation experiments on the ions generated by either photofragmentation or CID.

\section{Acknowledgments}

This work was supported by National Science Foundation Grants CHE-0518234 and CHE-0431991 and by a grant from the National Center for Research Resources, a component of the National Institutes of Health (NIH-NCRR) for the National Center for Glycomics and Glycoproteomics Grant RR018942.

\section{References}

1. Varki, A. E. A. Essentials of Glycobiology; Cold Spring Harbor Laboratory Press: New York, 1999.

2. Campbell, C. T.; Yarema, K. J. Large-scale Approaches for Glycobiology. Genome Biol. 2005, 6, 231-238.

3. Helenius, A.; Aebi, M. Intracellular Functions of N-Linked Glycans. Science 2001, 291, 2364-2369.

4. Rudd, P. M.; Elliott, T.; Cresswell, P.; Wilson, I. A.; Dwek, R. A. Glycosylation and the Immune System. Science 2001, 291, 2370-2376.

5. Shriver, Z.; Raguram, S.; Sasisekharan, R. Glycomics: A Pathway to a Class of New and Improved Therapeutics. Nat. Rev. Drug Discov. 2004, 3, 863-873.

6. Bianco, G. A.; Toscano, M. A.; Ilarregui, J. M.; Rabinovich, G. A. Impact of Protein-Glycan Interactions in the Regulation of Autoimmunity and Chronic Inflammation. Autoimmun. Rev. 2006, 5, 349-356.

7. Varki, A. Biological Roles of Oligosaccharides: All of the Theories Are Correct. Glycobiology 1993, 3, 97-130.

8. Mechref, Y.; Novotny, M. V. Structural Investigations of Glycoconjugates at High Sensitivity. Chem. Rev. 2002, 102, 321-369.

9. Reinhold, V. N.; Reinhold, B. B.; Costello, C. E. Carbohydrate Molecular Weight Profiling, Sequence, Linkage and Branching Data: ES-MS and CID. Anal. Chem. 1995, 67, 1772-1784.

10. Dommon, B.; Muller, D. R.; Richter, W. J. High Performance Tandem Mass Spectrometry for Sequence, Branching and Interglycosidic Linkage Analysis of Peracetylated Oligosaccharides. Biomed. Environ. Mass Spectrom. 1990, 19, 390-402.

11. Dommon, B.; Muller, D. R.; Richter, W. J. Determination of Interglycosidic Linkages in Disaccharides by High Performance Tandem Mass Spectrometry. Int. J. Mass Spectrom. Ion Processes 1990, 100, 301-311.

12. Garozzo, D.; Giuffrida, M.; Impallomeni, G.; Ballistreri, A.; Montaudo, G. Determination of Linkage Position and Identification of the Reducing End in Linear Oligosaccharides by Negative Ion Fast Atom Bombardment Mass Spectrometry. Anal. Chem. 1990, 62, 279-286.

13. Spengler, B.; Dolce, J. W.; Cotter, R. J. Infrared Laser Desorption Mass Spectrometry of Oligosaccharides: Fragmentation Mechanisms and Isomer Analysis. Anal. Chem. 1990, 62, 1731-1737.

14. Carroll, J. A.; Ngoka, L.; Mccullough, S.; Gard, E.; Jones, A. D.; Lebrilla, C. B. Quadrupole Fourier Transform Mass Spectrometry of Oligosaccharides. Anal. Chem. 1991, 63, 2526-2529.

15. Carroll, J. A.; Ngoka, L.; Beggs, C. G.; Lebrilla, C. B. Liquid Secondary Ion Mass Spectrometry/Fourier Transform Mass Spectrometry of Oligosaccharide Anions. Anal. Chem. 1993, 65, 1582-1587.

16. Harvey, D. J.; Rudd, P. M.; Bateman, R. H.; Bordoli, R. S.; Howes, K.; Hoyes, J. B.; Vickers, R. G. Examination of Complex Oligosaccharides by Matrix-Assisted Laser Desorption/Ionization Mass Spectrometry on Time-of-Flight and Magnetic Sector Instruments. Org. Mass Spectrom. 1994, 29, 753-765.

17. Harvey, D. J.; Naven, T. J. P.; Kuster, B.; Bateman, R. H.; Green, M. R.; Critchley, G. Comparison of Fragmentation Modes for the Structural Determination of Complex Oligosaccharides Ionized by Matrix-Assisted Laser Desorption/Ionization Mass Spectrometry. Rapid Commun. Mass Spectrom. 1995, 9, 1556-1561.
18. Visuex, N.; deHoffmann, E.; Dommon, B. Structural Analysis of Permethylated Oligosaccharides by Electrospray Tandem Mass Spectrometry. Anal. Chem. 1997, 69, 3193-3198.

19. Weiskopf, A. S.; Vouros, P.; Harvey, D. J. Characterization of Oligosaccharide Composition and Structure by Quadrupole Ion Trap Mass Spectrometry. Rapid Commun. Mass Spectrom. 1997, 11, 1493-1504.

20. Naven, T. J. P.; Harvey, D. J.; Brown, J.; Critchley, G. Fragmentation of Complex Carbohydrates Following Ionization by Matrix-Assisted Laser Desorption with an Instrument Fitted with Time-Lag Focusing. Rapid Commun. Mass Spectrom. 1997, 11, 1681-1686.

21. Harvey, D. J. Matrix-Assisted Laser Desorption/Ionization Mass Spectrometry of Carbohydrates. Mass Spectrom. Rev. 1999, 18, 349-451.

22. Mechref, Y.; Baker, A. G.; Novotny, M. V. Matrix-Assisted Laser Desorption/Ionization Mass Spectrometry of Neutral and Acidic Oligosaccharides with Collision-Induced Dissociation. Carbohydr. Res. 1998, 313, 145-155.

23. Weiskopf, A. S.; Vouros, P.; Harvey, D. J. Electrospray Ionization-Ion Trap Mass Spectrometry for Structural Analysis of Complex N-Linked Glycoprotein Oligosaccharides. Anal. Chem. 1998, 70, 4441-4447.

24. Sheeley, D. M.; Reinhold, V. N. Structural Characterization of Carbohydrate Sequence, Linkage, and Branching in a Quadrupole Ion Trap Mass Spectrometer: Neutral Oligosaccharides and N-Linked Glycans. Anal. Chem. 1998, 70, 3053-3059.

25. Konig, S.; Leary, J. A. Evidence for Linkage Position Determination in Cobalt Co-ordinated Pentasaccharides Using Ion Trap Mass Spectrometry. J. Am. Soc. Mass Spectrom. 1998, 9, 1125-1134.

26. Solouki, T.; Reinhold, B. B.; Costello, C. E.; O'Malley, M.; Guan, S. H. Marshall, A. G. Electrospray Ionization and Matrix-Assisted Laser Desorption/Ionization Fourier Transform Ion Cyclotron Resonance Mass Spectrometry of Permethylated Oligosaccharides. Anal. Chem. $1998,70,857-864$.

27. Harvey, D. J. Electrospray Mass Spectrometry and Fragmentation of N-Linked Carbohydrates Derivatized at the Reducing Terminus. J. Am. Soc. Mass Spectrom. 2000, 11, 900-915.

28. Harvey, D. J. Collision-Induced Fragmentation of Underivatized NLinked Carbohydrates Ionized by Electrospray. J. Mass Spectrom. 2000, 35, 1178-1190.

29. Harvey, D. J.; Bateman, R. H.; Bordoli, R. S.; Tyldesley, R. Ionisation and Fragmentation of Complex Glycans with a Quadrupole Time-of-Fligh Mass Spectrometer Fitted with a Matrix-Assisted Laser Desorption/ Ionisation Ion Source. Rapid Commun. Mass Spectrom. 2000, 14, 2135 2142 .

30. Hunnam, V.; Harvey, D. J.; Priestman, D. A.; Bateman, R. H.; Bordoli, R. S.; Tyldesley, R. Ionization and Fragmentation of Neutral and Acidic Glycosphingolipids with a Q-TOF Mass Spectrometer Fitted with a MALDI Ion Source. I. Am. Soc. Mass Spectrom. 2001, 12, 1220-1225.

31. Spengler, B.; Kirsch, D.; Kaufmann, R.; Lemoine, J. Structural Analysis of Branched Oligosaccharides Using Post-Source Decay in MatrixAssisted Laser Desorption Ionization Mass Spectrometry. Org. Mass Spectrom. 1994, 12, 782-787.

32. Sato, Y.; Suzuki, M.; Nirasawa, T.; Suzuki, A.; Endo, T. Microsequencing of Glycans Using 2-Aminobenzamide and MALDI-TOF Mass Spectrometry: Occurrence of Unique Linkage-Dependent Fragmentation. Anal. Chem. 2000, 72, 1207-1216.

33. Rouse, J. C.: Strang A-M. Y Yu, W ; Vath, J. E. Isomeric Differentiation of Asparagine-Linked Oligosaccharides by Matrix-Assisted Laser Desorption-Ionization Postsource Decay Time-of-Flight Mass Spectrometry. Anal. Biochem. 1998, 256, 33-46.

34. Mechref, Y.; Novotny, M. V.; Krishnan, C. Structural Characterization of Oligosaccharides Using Maldi-TOF/TOF Tandem Mass Spectrometry. Anal. Chem. 2003, 75, 4895-4903.

35. Mechref, Y.; Kang, P.; Novotny, M. V. Differentiating Structural Isomers of Sialylated Glycans by Matrix-Assisted Laser Desorption/Ionization Time-of-Flight/Time-of-Flight Tandem Mass Spectrometry. Rapid Commun. Mass Spectrom. 2006, 20, 1381-1389.

36. Spina, E. S. L.; Romeo, D.; Impallomeni, G.; Garozzo, D.; Waidelich, D. Glueckmann, M. New Fragmentation Mechanisms in Matrix-Assisted Laser desorption/Ionization Time-of-Flight/Time-of-Flight Tandem Mass Spectrometry of Carbohydrates. Rapid Commun. Mass Spectrom. 2004, 18, 392-398.

37. Morelle, W.; Slomianny, M.-C.; Diemer, H.; Schaeffer, C.; van Dorsselaer, A.; Michalski, J.-C. Fragmentation Characteristics of Neutral N-Linked Glycans Using a MALDI-TOF/TOF Tandem Mass Spectometer. Anal. Chem. 2004, 76, 2343-2354.

38. Morelle, W.: Slomianny, M.-C.; Diemer, H.; Schaeffer, C.; van Dorsselaer, A.; Michalski, J.-C. Fragmentation Characteristics of Permethylated Oligosaccharides Using a Matrix-Assisted Laser Desorption/Ionization Two-Stage Time-of-Flight (TOF/TOF) Tandem Mass Spectrometer. Rapid Commun. Mass Spectrom. 2004, 18, 2637-2649.

39. Ashline, D. J.; Lapadula, A. J.; Liu, Y. H.; Lin, M.; Grace, M.; Pramanik B.; Reinhold, V. N. Carbohydrate Structural Isomers Analyzed by Sequential Mass Spectrometry. Anal. Chem. 2007, 79, 3830-3842.

40. Shi, S. D.-H.; Hendrickson, C. L.; Marshall, A. G.; Seigel, M. M.; Kong F.; Carter, G. T. Structural Validation of Saccharomicins by High Resolution and High Mass Accuracy Fourier Transform-Ion Cyclotron Resonance-Mass Spectrometry and Infrared Multiphoton Dissociation Tandem Mass Spectrometry. J. Am. Soc. Mass Spectrom. 1999, 10, $1285-1290$.

41. Xie, Y.; Lebrilla, C. B. Infrared Multiphoton Dissociation of Alkali Metal-Coordinated Oligosaccharides. Anal. Chem. 2003, 75, 1590-1598. 
42. Zhang, J.; Schubothe, K.; Li, B.; Russell, S.; Lebrilla, C. B. Infrared Multiphoton Dissociation of O-Linked Mucin-Type Oligosaccharides. Anal. Chem. 2005, 77, 208-214.

43. Lancaster, K. S.; An, H. J.; Li, B.; Lebrilla, C. B. Interrogation of N-Linked Oligosaccharides Using Infrared Multiphoton Dissociation in FT-ICR Mass Spectrometry. Anal. Chem. 2006, 78, 4990-4997.

44. Budnik, B. A.; Haselmann, K. F.; Elkin, Y.; Gorbach, V. I.; Zuberev, R. A. Applications of Electron-Ion Dissociation Reactions for Analysis of Polycationic Chitooligosaccharides in Fourier Transform Mass Spectrometry. Anal. Chem. 2003, 75, 5994-6001.

45. Adamson, J. T.; Hakansson, K. Electron Capture Dissociation of Oligosaccharides Ionized with Alkali, Alkaline Earth, and Transition Metals. Anal. Chem. 2007, 79, 2901-2910.

46. Thompson, M. S.; Cui, W.; Reilly, J. P. Fragmentation of Singly-charged Peptides by Photodissociation at $157 \mathrm{~nm}$. Angew. Chem. Int. Ed. Engl. 2004, 43, 4791-4794

47. Cui, W.; Thompson, M. S.; Reilly, J. P. Pathways of Peptide Ion Fragmentation Induced by Vacuum Ultraviolet Light. J. Am. Soc. Mass Spectrom. 2005, 16, 1384-1398.

48. Kim, T. Y.; Thompson, M. S.; Reilly, J. P. Peptide Photodissociation at $157 \mathrm{~nm}$ in a Linear Ion Trap Mass Spectrometer. Rapid Commun. Mass Spectrom. 2005, 19, 1657-1665.

49. Devakumar, A.; Thompson, M. S.; Reilly, J. P. Fragmentation of Oligosaccharide Ions with $157 \mathrm{~nm}$ Vacuum Ultraviolet Light. Rapid Commun. Mass Spectrom. 2005, 19, 2313-2320.

50. Devakumar, A.; Mechref, Y.; Kang, P.; Novotny, M. V.; Reilly, J. P. Laser-Induced Photofragmentation of Neutral and Acidic Glycans inside an Ion-Trap Mass Spectrometer. Rapid Commun. Mass Spectrom. 2007, 21, 1452-1460.

51. Mechref, Y.; Novotny, M. V. Matrix-Assisted Laser Desorption/Ionization Mass Spectrometry of Acidic Glycoconjugates Facilitated by the Use of Spermine as a Co-matrix. J. Am. Soc. Mass Spectrom. 1998, 9, 1293-1302.

52. Kang, P.; Mechref, Y.; Klouckova, I.; Novotny, M. V. Solid-Phase Permethylation of Glycans for Mass Spectrometric Analysis. Rapid Commun. Mass Spectrom. 2005, 19, 3421-3428.

53. Devakumar, A.; O’Dell, D. K.; Walker, J. M.; Reilly, J. P. Structural Analysis of Leukotriene $\mathrm{C}_{4}$ isomers Using Collisional Activation and $157 \mathrm{~nm}$ Photodissociation. J. Am. Soc. Mass Spectrom. 2007, 19, 14-26.
54. Payne, A. H.; Glish, G. L. Thermally Assisted Infrared Multiphoton Photodissociation in a Quadrupole Ion Trap. Anal. Chem. 2001, 73, 3542-3548.

55. Wilson, J. J.; Brodbelt, J. S. MS/MS Simplification by $355 \mathrm{~nm}$ Ultraviolet Photodissociation of Chromophore-Derivatized Peptides in a Quadrupole Ion Trap. Anal. Chem. 2007, 79, 7883-7892.

56. Dommon, B.; Costello, C. E. A Systematic Nomenclature for Carbohydrate Fragmentations in FAB-MS/MS Spectra of Glycoconjugates. Glycoconjugate J. 1988, 5, 397-409.

57. Spina, E. S. L.; Romeo, D.; Impallomeni, G.; Garozzo, D.; Waidelich, D. Glueckmann, M. New Fragmentation Mechanisms in Matrix-Assisted Laser Desorption/Ionization Time-of-Flight/Time-of-Flight Tandem Mass Spectrometry of Carbohydrates. Rapid Commun. Mass Spectrom. 2004, 18, 392-398.

58. Stephens, E.; Maslen, S. L.; Green, L. G.; Williams, D. H. Fragmentation Characteristics of Neutral N-linked Glycans Using a MALDI-TOF/TOF Tandem Mass Spectrometer. Anal. Chem. 2004, 76, 2343-2354.

59. Silva, M. L. C. D.; Stubbs, H. J.; Tamura, T.; Rice, K. G. ${ }^{1}$ H NMR Characterization of a Hen Ovalbumin Tyrosinamide N-Linked Oligosaccharide Library. Arch. Biochem. Biophys. 1995, 318, 465-475.

60. Kuster, B.; Naven, T. J. P.; Harvey, D. J. Rapid Approach for Sequencing Neutral Oligosaccharides by Exoglycosidase Digestion and MatrixAssisted Laser Desorption/Ionization Time-of-Flight Mass Spectrometry. J. Mass Spectrom. 1996, 31, 1131-1140.

61. North, S.; Birrell, H.; Camilleri, P. Postive and Negative Ion MatrixAssisted Laser Desorption/Ionization Time-of-Flight Mass Spectrometric Analysis of Complex Glycans Released from Hen Ovalbumin and Derivatized with 2-Aminoacridone. Rapid Commun. Mass Spectrom. 1998, 12, 349-356.

62. Lattova, E.; Perreault, H.; Krokhin, O. Matrix-Assisted Laser Desorption/Ionization Tandem Mass Spectrometry and Post-Source Decay Fragmentation Study of Phenylhydrazones of N-Linked Oligosaccharides from Ovalbumin. J. Am. Soc. Mass Spectrom. 2004, 15, 725-735.

63. Lattova, E.; Perreault, H. Profilling of N-Linked Oligosaccharides Using Phenylhydrazine Derivatization and Mass Spectrometry. J. Chromatogr. A 2003, 1016, 71-87.

64. Harvey, D. J. Fragmentation of Negative Ions from Carbohydrates: Part 3. Fragmentation of Hybrid and Complex N-Linked Glycans. J. Am. Soc. Mass Spectrom. 2005, 16, 647-659. 